\title{
Are Online Parasites Really Different from Lurkers?
}

\author{
Shaoyang Bu \\ Chonnam National University \\ charman1024@naver.com
}

\author{
Liguo Lou \\ Ningbo University of Technology \\ alexlou@nbut.edu.cn
}

\author{
Joon Koh \\ Chonnam National University \\ kjoon@chonnam.ac.kr
}

\begin{abstract}
With the development of digital technology, the internet environment has dramatically changed the way people share information, which has been changed by different types of sources, making it convenient to obtain information. The lurking phenomenon in the network is becoming increasingly common, and previous studies have been conducted on lurkers on the internet with shifting focus from active users to passive users. Under these circumstances, this tries to conceptualize a new type of passive users, titled as "online parasites" who focus on obtaining information by utilizing the internet or their host to achieve their other purposes. The aim is to deeply understand these users and clearly distinguish them from other types of users such as lurkers.
\end{abstract}

\section{Introduction}

Recently, the network environment has changed dramatically owing to various technological developments. Media outlets, represented by ordinary mobile phones, newspapers, magazines, radio, and television just over a decade ago, are rapidly losing their former monopoly status as new media such as smart phones and tablet PCs rapidly proliferate [1]. The use of the internet becomes essential to participation in the global economy, constantly bringing convenience to our lives. As of 2018, there were more than 312 million internet users in the United States, and only $10 \%$ of American adults said they would not use the internet in 2019 [2]. In addition, the combination of the deployment of smart platforms and the high-speed internet provides a diverse and optimal environment for users [3]. It changes the way we conduct information production and communication. As a result, internet users can quickly obtain information such as images and videos.

As the information society progressed rapidly, people emphasized the efficiency of searching for information, and efficiency became a more meaningful measure. However, the more information we encounter, the more stress we may get. For example,
Korhonen et al. found that when purchasing a product, the quality of product choice decreases as the quantity of information provided increases, making it difficult to objectively judge [4]. Considering the contact with mass information, it can cause internet cognitive fatigue associated with motivations/impacts, behaviors, and empirical outcomes resulting from continuous mental work [5]. Especially on social media, instant messages often reflect grammatical and spelling errors, internet slang, and abbreviations since they are poorly structured and limited to one or two words, all of which require more cognitive processing [6]. Due to the many influences, such as cognitive fatigue, only a small number of internet users actively utilize the internet as an effective means.

Regarding online user participation, Nielsen describes low levels of involvement and information sharing as characteristics of the online environment and defines by the 90-9-1 rule [7]. That is, $90 \%$ of users read or observe (no contribution), $9 \%$ sometimes contribute, and remaining $1 \%$ actively participate and make up most of the donations. It is already common for most users to obtain information or consume media content through the internet. Users who produce little or no content and perform other activities (e.g., reading) quietly are called "lurkers" and their behavior is called "lurking" $[8,9]$. As the phenomenon of users lurking on the internet has become universal, research has been conducted regarding personal characteristics [10], information privacy [9], role perspective [11], transactional distance, and interaction types [12]. A study on social media established that the lurking degree of lurkers in the network is different [8]. Although the study did not grade the levels of lurking, the author advocated its usefulness. Moreover, a survey of online review sites found that a group of passive users showed a high degree of participation [13]. That is, not all passive users conduct inactive behaviors on the internet with a negative attitude. Some passive users even behave in the online community but do not contribute to the community. They also actively obtain information from the network but do not provide. Thus, in this study, we define the specific users who actively 
obtain the desired information from the internet but do not particularly contribute as "online parasites."

Considering the idea that passive users are the potential audience and customers, turning them into active participants has been regarded as an essential goal of the online community [14]. It becomes particularly important to analyze passive users and understand them more deeply, but not many theories have been established by systematically approaching inactive users [15]. Furthermore, collaboration via cross-border systems such as virtual communities is affected by participant commitment and trust, and especially quality in collaboration by cross-system integration is critical for the community survival and development. Information sharing and community activities across cultural/national borders lead to synergy triggering productivity. There are two objectives of this research. The first goal is to use the interview method with cross-cultural environmental interviewees and analyze its materials to identify and define a new type of network users called "online parasites." The second is to distinguish between online parasites and other types of users such as lurkers at the level of user interaction and contribution. Since it has a higher level of information retention and activity than ordinary passive users, companies that operate online communities considers the needs and meaning of "online parasites" when activating inactive users. This draft is also expected to deeply understand online user behaviors regarding further collaboration across national borders.

\section{Conceptual background}

\subsection{Passive users vs. lurkers}

While researching and classifying internet users, the "active-passive" dichotomy appears to be the most commonly used method, and most research has focused on active, visible users. The active-passive quantitative measurement division generally includes the duration of membership, the time spent on the internet, the number of visits, the number of clicks/views of the content, the number of contributions, and the density of social interaction with others [14]. Just like YouTube users are mostly passive, only a part of them actively participates, and their participation in active interaction with others is even lower. Interactive participants pursuing social relationships are more likely to view YouTube as an online community, while non-interactive and passive users use YouTube as a TV-like channel [16]. In addition, participation in virtual communities includes passively viewing and actively posting [17], or classified users as content contributors and content consumers [18]. Users are free to choose to write blog posts, comment on content, modify Wiki articles, upload their photos, or take passive actions to show inaction. Moreover, the punishment of noncontributors is unlikely to be a viable option, especially in the case of voluntary participation; such behavior may cause the punished participants to withdraw, thereby destroying the system [10].

Regarding the concept of passive users, Wang et al. interpreted active users as producers who produce content such as updates and comments on other people's posts, and passive SNS users are described as directed or random consumers of social content [19]. They just follow several profiles they like and never generate any content that could be gathered or analyzed [20]. The definition of a user in terms of active and passive appears to be no longer limited to the direct control of technology [21], but focuses on the user's participation method and degree.

While passive users usually show lower levels of user participation, lurkers are related to nonparticipation and non-posting behaviors. Liu et al. mentioned some conceptual overlap between lurking and passive use of SNS, that is, the non-publishing behavior on SNS, which leads to lurker related research mainly focused on motivation [11]. "Lurker" is often used to describe someone who observes what is going on and remains silent but does not participate and is thus associated with observation, silence, inactivity/passivity, invisibility, or bystander behavior [22]. Research explains lurker as someone who only browses content without disclosing personal information [23], does not send messages [24], and stops contributing [25]. Such users can also be called Legitimate Peripheral Participants ([12], [26]).

Although researchers often develop their new definition, it can be noticed that when defining lurker, no-creating content and browsing behavior were mentioned at the same time (Table 1). In addition, these definitions in the research do not consider the interaction between users and communities, users and content (for example, click the "Like," "Favorite" buttons). How do users perceive this interaction between users and content? Do they consider it as a contribution to the community? This is the focus of this research.

Finding suitable methods to study passive users poses a significant challenge because they usually remain in hiding and leave fewer traces, making it difficult to track their behavior [27]. The age of big data sets makes it convenient to track the digital footprint of these passive users on the network. It can, therefore, make lurkers and their passive activities more visible by displaying website usage [14]. As 
such, Nechaev conducted a study on how to hide their digital footprint to protect privacy for passive users who do not want to be noticed during activities on social media [20]. Lurking may not be the user behavior that social media expects. Since there are not sufficient users who actively contribute content, the social media community may shrink [8]. However, the presence of lurkers is practically meaningful. If every member of the community is involved, a lot of repetitive information will be generated, and it is necessary to help filter out what they do not need [28].

Table 1. Definition of lurker/lurking

\begin{tabular}{|c|l|}
\hline Name & \multicolumn{1}{|c|}{ Explanation } \\
\hline Lurkers0 & $\begin{array}{l}\text { lurkers never send messages to online } \\
\text { communities, remain silent all the time, } \\
\text { and read more postings than they create, } \\
\text { edit, or write }\end{array}$ \\
\hline Lurking0 & $\begin{array}{l}\text { The degree by which a user only browses } \\
\text { contents without disclosing personal } \\
\text { private information in SNSs }\end{array}$ \\
\hline Lurking0 & $\begin{array}{l}\text { The more number of days are there in the } \\
\text { 'last activity' category, the higher the } \\
\text { lurking behavior. This occurs when users } \\
\text { stop contributing on the platform. }\end{array}$ \\
\hline $\begin{array}{c}\text { Lurking } \\
\text { intention0 }\end{array}$ & $\begin{array}{l}\text { The intention to decrease or discontinue } \\
\text { posting content on SNSs }\end{array}$ \\
\hline Lurker0 & $\begin{array}{l}\text { User is a lurker during a time interval with } \\
\text { duration a week, if the number of tweets } \\
\text { he/she posts in the time interval is not } \\
\text { more than a lurking threshold } 2\end{array}$ \\
\hline $\begin{array}{c}\text { Legitimate } \\
\text { Peripheral } \\
\text { Participants } \\
0,0\end{array}$ & $\begin{array}{l}\text { They read but contribute little or no } \\
\text { content of their own }\end{array}$ \\
\hline
\end{tabular}

Some lurkers are free-riders, but many lurk for other reasons, including pro-social and altruistic reasons [22]. One reason is their demand for information. For example, the lurkers in the learning community pay more attention to their interaction with the content, that is, information acquisition needs [12]. Moreover, the employee does not have any new or important things to post, but it does not exclude the possibility that he/she can pass the information of the ESM outside the scope of the software as a beneficial output [29]. In addition, employees who lurk do not openly seek help, but they actively consume content (e.g., problems and solutions proposed by colleagues) to improve their business performance to meet expectations [18]. Thus, such lurkers exist who do not contribute to the network but actively obtain the desired information from the internet to meet their other purposes. The internet is a convenient and fast channel for them to obtain information. It is not their primary purpose, like general passive users, to monitor other people's lives such as browsing and viewing people's profiles or the contents of posts on SNS [30]. That is because processing information without contributing can be a high-performance, easy-to-use, socially supported, and a resource-saving way to improve work efficiency.

Passive users usually refer to users whose access to technology is restricted when using technology [31]. Modern people have a tendency to rely heavily on information behaviors conducted through the internet, and they have a high level of execution capability for information acquisition and information retrieval behaviors conducted through network technology. So far, passive users had a broader meaning, for instance, Horng and others considered Lurker as a kind of passive user [17]. In this regard, based on the active level of user participation, we recommend that online users be divided into two categories: active users and passive users. Thus, passive users include inactive users, lurkers, and online parasites. Inactive users are the least active and have a negative attitude towards the use of technology.

\subsection{Online parasites}

As mentioned before, we explained "online parasites" as users who actively obtain the desired information from the internet, but do not contribute to the internet. The information obtaining behavior here can be considered as "information seeking behavior" and "information searching behavior." Moreover, Wilson suggested that "information need" was a secondary order need that arose out of the desire to satisfy the primary needs ([32],[33]). "Online parasites" are often strategic while participating in online activities, which makes them spend a lot of time searching until they obtain the information they need. In other words, to satisfy the primary needs (such as raising their awareness, improving professional skills, or solving the problems at hand), they will utilize the information obtained in a flexible way like "active lurker as practitioner" [12].

There are similarities and differences between a lurker and an "online parasite." The research on lurker is mainly to classify members in the online community. That is, lurkers are registered users, and they browse contents in the online community from time to time. It is extremely likely that "online parasites" have not been registered as a member user, because the content of many sites is visible to everyone, that is, internet users can search and see it. In addition, when they must register as a user to view detailed content, they may choose to register as a member or give up (switch to 
other pages) according to the importance of the content. Even if they complete the registration steps, they might not consider themselves as members like other users. Therefore, compared with other users, their emotional bonds or sense of belonging to online communities and organizations may be lower.

They see the online community more as a channel to obtain information. They do not pay much attention to perfecting their personally identifiable information because it is not important when compared to content. Due to time and recognition limitations, increased role conflicts or role overloads can prevent users in the online community from responding to them effectively [11]. However, this is not the case with "online parasites." Moreover, they are also extremely talented at various environments and use multiple methods (such as search engines, blogs, SNS, and online communities) to achieve their goal of obtaining information for their own or organizational activities. They often use the "like" and "favorite" functions when they find a content useful. It is convenient for them to view these contents in the future and integrate this information into their own information database, or apply it to life and study. Since they are more focused on collecting information rather than interacting with other users, they learn more in certain professional fields.

We have provided a new definition to this category of users and clarified its relationship with similar user types, hoping to create an in-depth understanding of passive users and new insights for online community developers, managers, moderators, and software designers. Moreover, online parasites have the ability and resources to share, if we can find a suitable method to encourage them to produce and contribute content; it can make the online community more active and develop better. Like the existing method, in conjunction with the reward mechanism, send them invitations and reminders to encourage the production of content to obtain access rights or spiritual or material rewards. Consequently, understanding the evolution and changes of users in the information environment has become particularly important to choose a more correct way.

\section{Method}

\subsection{Interview procedure}

We conducted preliminary interviews with seven participants to observe how they use the internet, why they join the online community, and how they obtain information from the online community, regardless of whether they have the experience in posting messages in the online community.

Interviews were conducted from May 25, 2020 to July 7, 2020; each interview took 25 minutes on average. We negotiated the location and time with the study participants in advance, subsequently conducted a one-to-one interview at a cafe or a quiet place near the participant's school.

In order to facilitate the analysis of this article, the interview process was recorded with the consent of the participants, and the recording was performed using a smart phone. After the second interview, the content of the interview was analyzed, and the third to seventh interviews were centered on the information that required to be confirmed or on the content that required more information. The transcription of the interview recording was conducted by the researcher using software and was revised again. The text of the interview after the transfer is in 71 pages in total (A4 paper, 11-point, double line spacing).

\subsection{Composition of interview questions}

The questions used in the interview are based on research purposes, about the use of personal networks, and are open questions to ensure participants' experiences of data. Table 2 lists the interview questions. We made the necessary adjustments flexibly according to the actual situation during the interview, such as the way and sequence of questions and the way the interviewees answered.

The semi-structured questionnaire used in this study refers to the article by Takahashi et al. [29]. In addition, to ensure the validity of the questionnaire content, participants were shown the transcribed interview text and asked whether it reflected their thoughts correctly and appropriately. In this way, the subjectivity of the researcher was eliminated, which ensured that the results would not lead to deviations.

\section{Table 2. Interview questions}

\begin{tabular}{|l|}
\hline Do you use the Internet often? How often? \\
\hline Please explain how you feel when you use the Internet. \\
\hline $\begin{array}{l}\text { Do you have any online communities that you use } \\
\text { frequently? Why? }\end{array}$ \\
\hline $\begin{array}{l}\text { What do you think about the online community you're } \\
\text { using? }\end{array}$ \\
\hline $\begin{array}{l}\text { Have you ever posted your thoughts or content online? } \\
\text { Why? }\end{array}$ \\
\hline
\end{tabular}

\subsection{Selection of participants}


Strauss \& Corbin introduced three different theoretical sampling methods: open sampling, relational and variational sampling, and discriminating sampling [34]. Open sampling is based on the research question, selects the research object that can provide the maximum coverage of the research question for the interview, so as to cover all aspects of the research phenomenon. Relational and variational sampling refers to more targeted selection of interviewees based on the real-time collation and analysis of interview materials, and a careful combing of the theoretical concepts emerging from the materials. Discriminating sampling means that with the increase of interview data, selecting those survey respondents who will help to revise further and improve the theory to conduct interviews to establish theoretical assumptions. According to the actual research needs, we applied these three sampling methods flexibly to the semistructured interviews in the research.

A study on social media by Williams et al. [35] showed that $80 \%$ of their research sample is college students who consider themselves to be spectators rather than active users of social media. In another study on the social networking site "Facebook," $80.89 \%$ of the samples had junior college/college degree, and the 20 to 24 years old sample accounted for $73.46 \%$ of the total sample size [9]. Nowadays, college students grow with the development of the internet, and they can use the internet proficiently and are used to it. They make up the vast majority of network users, and a considerable number of them are parasitic or lurking on the network. A study on the internet usage of international students shows that they like to actively search for suitable learning methods and materials through the internet, or do economic activities related to the internet [36]. In addition, the internet plays an important role in solving the psychological stress of students studying abroad who are unable to adapt to other countries' life.

In the cross-border environment, it is suitable for capturing the diversity in various experiences in various situations and cultures, such as using Chinese SNS or community or Korean SNS. For example, there are significant differences in internet usage (including average daily usage time, usage purpose, etc.) between Chinese students in Korea and Chinese students in China. Further, the psychological maladjustment of Chinese students in South Korea and compulsive behavior related to internet use, as well as the degree of internet poisoning, are more prominent [37].

Therefore, in this study, the Chinese students who are over 20 years old and studying in South Korea were selected as the standard to select the interview participants.

\subsection{Characteristics of the participants}

Finally, seven participants were selected for the interview. Among them, there were 4 males and 3 females, with a minimum age of 25 years and a maximum of 33 years, and they were all graduate students (Table 3).

Table 3. Characteristics of the participants

\begin{tabular}{|c|c|c|c|}
\hline Participants & Age & Gender & Education \\
\hline 1 & 30 & Female & Graduate \\
\hline 2 & 27 & Female & Graduate \\
\hline 3 & 27 & Male & Graduate \\
\hline 4 & 33 & Male & Graduate \\
\hline 5 & 27 & Female & Graduate \\
\hline 6 & 25 & Male & Graduate \\
\hline 7 & 26 & Male & Graduate \\
\hline
\end{tabular}

\section{Findings}

\subsection{Definition of online parasites}

Lurkers are generally defined as users who neither post behaviors nor contribute to the online community. Contributions include shared bookmarks and feeds, posts in forums, shared items in task lists, blog entries or comments, shared files, and writing new or revised Wiki pages [38]. Never posting or providing no comment are interpreted as zero contribution [25]. As mentioned in Table 1, some researchers have described lurkers' non-publishing behavior irrespective of their interaction with the community and content (e.g., clicking on "like" button). In other words, users who neither publish content nor make the above contributions can be called as lurkers. However, Beike and Wirth-Beaumont [39] define lurker as an online community member who accesses and uses the online community but does not post messages. They do not strengthen the community through reciprocal relationships in any form and do not have any direct social interaction with the community. This shows that lurker's definition is very vague from the perspective of user interaction with content, and opinion is divided on it.

Is clicking "like" button a contribution behavior? Lee et al. [40] studied the "like" behavior on Facebook and stated that "enjoyment" is the main motivation for sample users to click "like." "Enjoyment" means that I 
like this content, agree with the content, relate to the content, and content is posted by a person who is important to me, and so on. In addition, "monetary incentive" (such as getting coupons, receiving a bargain deal) also has a positive effect on "like" click behavior. We received the following information in the interview:

“Sometimes I click 'like.' For example, the football team I like, or the football player I love, um, I click 'like' sometimes.

...Like the 'Zhiboba' (live-broadcasting platform), it actually has two functions, 'like' and 'unlike.' When someone said something bad about my favorite player or team, I would give an 'unlike.'

...Sometimes, for example, there is a lottery event on 'Weibo.' I have shared the content of the event a few times, and I feel, um, in this way I can participate in the lottery. If there is no reason for this, I actually rarely publish the content." (Participant 4 )

From this perspective, the primary reasons for clicking "like" include reflecting one's own attitude toward others or content, passing time, maintaining contact with others, and obtaining monetary rewards. It is not difficult to find that this kind of interactive behavior is mostly a reaction behavior made out of consideration of one's own position. In other words, the individual will most likely not view it as a contribution.

"I feel like what kind of posts have been made, this should be regarded as a contribution. But if, um, just click 'like', would you say any contribution? Even if there are some, it feels too small." (Participant 4)

However, from other perspectives, the user's interaction with the community and content does contribute to the community. For example, ShareNcare is a Facebook-based social sharing donation platform business that was established in 2015 with the aim of solving social problems through donations. This website creates and uploads the stories of people who need help. If netizens click "like" or share the content after reading the story, the sponsoring company will donate instead of netizens. Enterprises will also enjoy the publicity effect based on the spread of the story. In addition, a large number of lurkers may increase the popularity of the community through numbers as they will generate website traffic and increase clicks [41]. Or, the lurkers produce the reading mark of the producer's work through reading, which greatly inspires the producer [42].

"Users are actively using it; I think it is a contribution. For example, if an app is developed, if no one uses it, it will disappear, and it will not be improved. As soon as there are more users, it will actively improve, and then this APP will become more and more popular." (Participant 2)
In summary, we suggest clarifying the relationship between the active user, inactive user, lurker, and online parasite according to users' interaction behaviors and the perceived contributions to the community. Perceived contribution refers to the user's perception to the internet or the community, not from the perspective of other members or the community. The details are shown in Table 4. Active users have high autonomy, such as YouTube bloggers. Inactive users use the network passively; they need guidance and stimulation to cope with network changes. Although lurkers often use the internet, they rarely interact with content or other people because they do not want to leave any traces. However, they have a sense of value for their existence. Online parasite pays more attention to content and interacts with the interested parties. They are more self-centered and do not care about their contributions to other people and things, even if they accidentally do things that contribute to the community.

Table 4. Differences in user types

\begin{tabular}{|c|c|c|c|}
\hline \multicolumn{2}{|c|}{ Category } & \multicolumn{2}{c|}{ Interaction behavior } \\
\cline { 2 - 4 } & Yes & No \\
\hline \multirow{2}{*}{$\begin{array}{c}\text { Perceived } \\
\text { contributions to } \\
\text { community }\end{array}$} & Yes & Active users & Lurkers \\
\cline { 2 - 4 } & No & $\begin{array}{c}\text { Online } \\
\text { parasites }\end{array}$ & $\begin{array}{c}\text { Inactive } \\
\text { users }\end{array}$ \\
\hline
\end{tabular}

Considering users' interactive behavior and perceived community contributions, online parasites are defined as users who access and use the online community and produce interactive behaviors (such as likes and favorites) with the content but have no substantial content creation and contribution.

\subsection{Online parasites vs. Lurkers}

We re-examined lurkers and online parasites, analyzed the content of the interview, compared the two, and obtained the following results.

First, both browse and obtain content in the network or online community without publishing information or content. When online parasites browse a content, if they have resonance or interest in the content, they will click on "like," "favorite," or "forward" to interact with the content. Lurkers do not exhibit such behavior. They are more inclined to just browse the content on the internet.

Second, most research confirms that a lurker is a member of the online community and has the identity of a member, although they do not contribute content ([38], [43]). However, online parasites exhibit a 
different behavior. For example, some users of Wiki, even if they do not register as members, they can browse information and content and are satisfied with this.

Online parasites usually try multiple methods while browsing the content they want. For example, when they cannot find the desired information by typing keywords, they will modify the search keywords, or use other search engines instead. Further, due to the regional restrictions on the use of songs, they might need to use multiple applications to hear their favorite music.

Online parasites enjoy using the internet and staying in the online community for a long time. This is different from lurkers logging in from time to time and checking for a short time.

"I watch TikTok a lot. An average of three or four hours each time, I feel." (Participant 5)

"It's super long from opening eyes to closing eyes. I estimate that $2 / 3$ of the internet time is spent on TikTok, mostly I'm watching TikTok, even I'm in the toilet..." (Participant 1)

Lurking is considered to be an early stage, in which a person attempts to understand the community and eventually develops sufficient understanding to start contributing. The lurker will grow into a contributor, and the important thing is that the visible actions in the community will increase over time [38]. This kind of user who has been lurking for a while and subsequently started posting content to the community is also called de-lurker [27]. However, online parasites appear to be satisfied with the existing usage habits.

Online parasites have a high desire for information, and they spend a lot of time on information behaviors such as searching for information. By doing so, they promote the process of work and study or solve problems in life to meet their own information demand and need for cognition. The timeliness of information acquisition on the internet, the diversity of information, and the accuracy of knowledge-based information are able to satisfy their pursuit of efficiency.

Online parasites, like real parasites, are particularly dependent on the internet. They go online every day and use the internet to fill their leisure time; the internet is their first and best choice for obtaining information.

"Anyway, as long as I am free, I go online, especially frequently." (Participant 5)

"Every day is basically, except for sleeping time, the internet basically accounts for half of the rest of my time." (Participant 1)

"I often go online, and it usually takes about six hours a day." (Participant 6)
"I think that apart from sleeping, eating, and studying, about four or five hours may be spent on the internet." (Participant 2)

The comparison in detail between online parasites and lurkers is displayed in Table 5.

Table 5. Online parasites vs. Lurkers

\begin{tabular}{|c|c|c|}
\hline Categories & Online parasites & Lurkers \\
\hline Posting & No & No \\
\hline Viewing & Yes & Yes \\
\hline Responses & Yes & No \\
\hline Membership & Not really & Yes \\
\hline $\begin{array}{c}\text { \# of participating } \\
\text { communities }\end{array}$ & More & Less \\
\hline $\begin{array}{c}\text { Duration time in the } \\
\text { community }\end{array}$ & More \\
\hline $\begin{array}{c}\text { Possibility of becoming } \\
\text { a poster }\end{array}$ & Low & High \\
\hline $\begin{array}{c}\text { Attitude towards } \\
\text { information acquisition }\end{array}$ & High & Low \\
\hline $\begin{array}{c}\text { Dependence on the } \\
\text { network }\end{array}$ & High & Normal \\
\hline
\end{tabular}

\subsection{Implications of the findings}

The development and evolution of the internet provides a lot of information resources for internet users to meet their needs. We tried to understand the different network usage behaviors of passive users/inactive users or other users from the perspective of information behavior. Information has carried most of the relationships that people use the internet. Compared to Lurker or passive receivers who read newspapers many years ago, most internet users now have a certain degree of enthusiasm like online parasites. The online parasite group accounts for the vast majority of the internet users. Therefore, conceptualizing online parasites and studying their motivations and behaviors will greatly impact the sustainable development of the internet and virtual community. This study has some theoretical and practical implications as follows:

First, this manuscript conducted a qualitative study with an interview approach to distinguish online parasites from lurkers, active users, and inactive users, which contributes to a better understanding of classifying internet users. This study reveals the differences between online parasites and lurkers with the interaction behavior and community contribution dimensions, which provides a new perspective to help 
researchers have a deeper understanding of users' changing internet usage behaviors and habits.

Second, this draft confirms that information acquisition is a prominent motivation of online parasites, which implies that marketers can satisfy their needs through sharing many types of brand contents. Compared to other marketing activities or programs, providing brand contents to the online parasites is a relatively cost-effective way.

Third, this article confirms that online parasites have network addiction tendency, that is, they spend a lot of time using the internet. Although network addiction is unhealthy for users' life wellbeing, it provides marketers more opportunities to interact with online parasites and push brand information to them.

Finally, this study suggests that the online parasites are not valueless for the firms. On the contrary, understanding their psychology and encouraging their behaviors would be helpful for improving the firms' marketing performances.

\section{Conclusion}

This draft attempted to conceptualize the online parasites who mainly acquire information and knowledge using the internet actively to achieve their purposes. That is, via this study, we want to deepen the understanding of these styled users as well as to distinguish them from other types of users such as lurkers or passive users. Furthermore, by exploring the differences of various types of internet community users, we discussed some implications of the findings regarding the management of communities themselves or firm's community-based marketing strategy. For instance, from the perspective of a company or application service provider, analyzing user behavior can better understand users' usage habits, classify users and provide them with personalized services, so as to gain better customer evaluation and improve customer loyalty.

Regarding the study limitations of this paper, first of all, the basic questions used in the interview are relatively simple, and some more targeted questions should be designed. Additionally, the group of participants was small and homogenous. To choose more and diversified samples, may get more information. Furthermore, the online behavior seems to be strongly dependent on the type of online communities which the user interacts with as well as the context. That is, the same user might play different roles in different online communities. Thus, we need stronger evidence to prove our point.

Terminologically, a parasite is an organism that lives in a host organism getting its food from or at the expense of its host. This is consistent with the meaning of online parasites described in this manuscript. That is, the dependence between people's information needs and the internet is like the symbiotic relationship between parasites and their hosts while users benefit from the internet and information is the nutritional needs of users. In daily life, online parasites only focus on obtaining resources provided by the internet or company to create their own benefits. Over time they will be detrimental to the company or service provider. Thus, we need to transform these type users into active users or eliminate them from their hosts.

Future research directions are as follows: based on the limitations of the conceptual level study like this research, we need to empirically validate our argument. To this end, it may be a good method to develop measurement items and conduct quantitative research to provide empirical evidence for this classification. In addition, it is desirable to consider more detailed behavioral comparisons between locals and foreigners (such as Koreans and Chinese in South Korea). Further, elaborated new emerging internet user typology related research is required.

\section{References}

[1] M.S. Shim, "A study on media repertoire", Korean Journal of Broadcasting and Telecommunication Studies, 21(2), 2007, pp. 351-390.

[2] Clement, J., Internet usage in the United States, Statistics \& Facts, 2019.

[3] S.Y. Kwon, S.W. Kim, "A study on usage form of video contents by multiple media users - Focused on Multiplatforming”, Design Convergence Study, 16(3), 2017, pp. 85-101.

[4] P.J. Korhonen, P. Malo, T. Pajala, N. Ravaja, O. Somervuori, and J. Wallenius, "Context matters: The impact of product type, emotional attachment and information overload on choice quality", European Journal of Operational Research, 264(1), 2018, pp. 270-279.

[5] J.C. Hong, M.Y. Hwang, H.W. Chang, K.H. Tai, Y.C. Kuo, and Y.H. Tsai, "Internet cognitive failure and fatigue relevant to learners' self- regulation and learning progress in English vocabulary with a calibration scheme", Journal of Computer Assisted Learning, 31(5), 2015, pp. 450-461.

[6] C.H. Chen, W.P. Lee, and J.Y. Huang, "Tracking and recognizing emotions in short text messages from online chatting services", Information Processing \& Management, 54(6), 2018, pp. 1325-1344.

[7] Nielsen, J. The 90-9-1 rule for participation inequality in social media and online communities. 2006. www.nngroup.com/articles/participation-inequality/ 
[8] W. Gong, E.P. Lim, and F. Zhu, "Characterizing silent users in social media communities", In Ninth International AAAI Conference on Web and Social Media, 2015.

[9] J. Ortiz, W.H. Chih, and F.S. Tsai, "Information privacy, consumer alienation, and lurking behavior in social networking sites", Computers in Human Behavior, 80, 2018, pp. 143-157.

[10] T. Choi, and P.J. Robertson, "Contributors and freeriders in collaborative governance: A computational exploration of social motivation and its effects", Journal of Public Administration Research and Theory, 29(3), 2019, pp. 394-413.

[11] X. Liu, Q. Min, D. Wu, and Z. Liu, How does social network diversity affect users' lurking intention toward social network services? A role perspective, Information \& Management, 103258. 2019.

[12] A. Bozkurt, A. Koutropoulos, L. Singh, and S. Honeychurch, On lurking: Multiple perspectives on lurking within an educational community, The Internet and Higher Education, 44, 100709, 2020.

[13] A. Munzel, and W.H. Kunz, "Creators, multipliers, and lurkers: who contributes and who benefits at online review sites", Journal of Service Management, 25(1), 2014, pp. 4974.

[14] S. Malinen, "Understanding user participation in online communities: A systematic literature review of empirical studies", Computers in human behavior, 46, 2015, pp. 228238.

[15] Y.Y. Hwang, K.Y. Lee, "Factors Associated with SNS Users' Lurking Intention", Journal of International Trade \& Commerce, 14(5), 2018, pp. 475-488.

[16] M.D. Shoham, A.B. Arora, and A.A. Busaidi, "Writing on the wall: An online 'community' of YouTube patrons as communication network or cyber-graffiti?" In Proceedings of the 46th Hawaii international conference on system sciences (HICSS), 2013, pp. 3951-3960.

[17] S.M. Horng, "A STUDY OF ACTIVE AND PASSIVE USER PARTICIPATION IN VIRTUAL COMMUNITIES", Journal of Electronic Commerce Research, 17(4), 2016, pp. 289-311.

[18] T.H. Engler, and P. Alpar, "Contribution and consumption of content in enterprise social media", Information Systems Management, 35(1), 2018, pp. 2-14.

[19] J.L. Wang, J. Gaskin, D.H. Rost, and D.A. Gentile, "The reciprocal relationship between passive social networking site (SNS) usage and users' subjective well-being", Social Science Computer Review, 36(5), 2018, pp. 511-522.

[20] Y. Nechaev, F. Corcoglioniti, and C. Giuliano,
Concealing Interests of Passive Users in Social Media, In BlackMirror@ ISWC, 2017.

[21] J. Xu, K. Le, A. Deitermann, and E. Montague, "How different types of users develop trust in technology: A qualitative analysis of the antecedents of active and passive user trust in a shared technology", Applied ergonomics, 45(6), 2014, pp. 1495-1503.

[22] N. Edelmann, "Reviewing the definitions of 'lurkers' and some implications for online research", Cyberpsychology, Behavior, and Social Networking, 16(9), 2013, pp. 645-649.

[23] B. Osatuyi, "Is lurking an anxiety-masking strategy on social media sites? The effects of lurking and computer anxiety on explaining information privacy concern on social media platforms", Computers in Human Behavior, 49(1), 2015, pp. 324-332.

[24] N. Sun, P.P.L. Rau, and L. Ma, "Understanding lurkers in online communities: A literature review", Computers in Human Behavior, 38, 2014, pp. 110-117.

[25] J. Wairimu, and F.K. Andoh-Baidoo, Understanding Lurking Behaviors in Open Innovation Communities: The Role of Social Capital, In American Conference on Information Systems, Association For Indformation Systems, 2018.

[26] S. Honeychurch, A. Bozkurt, L. Singh, and A. Koutropoulos, "Learners on the periphery: Lurkers as invisible learners", European Journal of Open, Distance and E-learning, 20(1), 2017, pp. 192-212.

[27] V. Soroka, and S. Rafaeli, "Invisible participants: How cultural capital relates to lurking behavior", In Proceedings of the 15th international conference on World Wide Web, 2006, pp. 163-172.

[28] A. Koutropoulos, S. Honeychurch, and L. Singh, Rethinking lurking, eLearn Magazine, 29, 2019.

[29] M. Takahashi, M. Fujimoto, and N. Yamasaki, "The active lurker: influence of an in-house online community on its outside environment", In Proceedings of the 2003 international ACM SIGGROUP conference on Supporting group work, 2003, pp. 1-10.

[30] P. Verduyn, D.S. Lee, J. Park, H. Shablack, A. Orvell, J. Bayer, ... and E. Kross, "Passive Facebook usage undermines affective well-being: Experimental and longitudinal evidence", Journal of Experimental Psychology: General, 144(2), 2015, pp. 480-488.

[31] J. Pal, U.S. Pawar, E.A. Brewer, and K. Toyama, "The case for multi-user design for computer aided learning in developing regions", Proceedings of the 15th international conference on World Wide Web, 2006, pp. 781-789.

[32] T.D. Wilson, "On user studies and information needs", 
Journal of Documentation, 37(1), 1981, pp. 3-15.

[33] T.D. Wilson, "Human information behavior", Informing Science, 3(2), 2000, pp. 49-56.

[34] Strauss, A., and J. Corbin. Basics of qualitative research. Sage publications, 1990.

[35] D.L. Williams, V.L. Crittenden, T. Keo, and P. McCarty, "The use of social media: an exploratory study of usage among digital natives: The use of social media", Journal of Public Affairs, 12(2), 2012, pp. 127-136.

[36] M. Wang, and M.S. Na, "A Study on Internet use of Chinese Students in Korea", Discourse and Policy in Social Science, 8(1), 2015, pp. 77-98.

[37] L. Zhang, S.Y. Kim, and M.S. Jang, "Internet usage and psychological maladaptation comparison of Chinese students studying in Korean university and Chinese university", Rehabilitation Therapy Education, 7(2), 2015, pp. 167-180.

[38] M. Muller, "Lurking as personal trait or situational disposition: lurking and contributing in enterprise social media", In Proceedings of the ACM 2012 conference on computer supported cooperative work, 2012, pp. 253-256.
[39] D. Beike, and B.E. Wirth, "Psychological closure as a memory phenomenon", Memory, 13(6), 2005, pp. 574-593.

[40] S.Y. Lee, S.S. Hansen, and J.K. Lee, "What makes us click 'like' on Facebook? Examining psychological, technological, and motivational factors on virtual endorsement", Computer Communications, 73, 2016, pp. 332-341.

[41] R. Cullen, and S. Morse, "Who's contributing: Do personality traits influence the level and type of participation in online communities", In Proceedings of the 44th Hawaii international conference on system sciences (HICSS), 2011, pp. 1-11.

[42] N. Edelmann, "13 What is Lurking? A Literature Review of Research on Lurking", The Psychology of Social Networking, 2016, pp. 159-174.

[43] J. Bishop, "The psychology of trolling and lurking: The role of defriending and gamification for increasing participation in online communities using seductive narratives" $[\mathrm{M}] / /$ Gamification for Human Factors Integration: Social, Education, and Psychological Issues, IGI Global, 2014, pp. 162-179. 